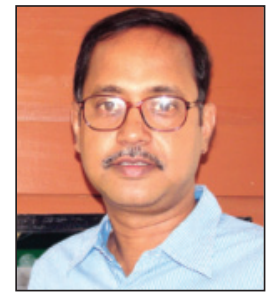

JOURNAL OF MINES, METALS \& FUELS www.jmmf.info

\title{
If you have a computer, you have a little slice of Spruce Pine
}

In the geologically mature and modest mountains of North Carolina, there is a little known town named Spruce Pine. A town of 2100 residents boasts of the hemlock trees, a type of spruce in the pine family, dotting the Toe river valley that also has given the town its name.The mountains there are the poor cousins of the likes of Himalayas but they more than make up for the heightsby their age. Age has brought out the best in them like the purity and luster of a vintage wine. They are the houses of the world's best quality quartz.

In the Toe River Valley, the mine holds out a view of a pickax, a gouged-out mountainside with ramps and terraces rising as ramparts over mounds of sand. This is a massive mine where multinational companies such as The QUARTZ Corp extract the purest quartz found anywhere on the earth. Because of its sheer purity, nearly every computer chip on the planet is manufactured using quartz from Spruce Pine.

"If you have a computer, you have a little slice of Spruce Pine," once said a local, Robin Townsend. She works at the Museum of North Carolina Minerals, where one can tap into a mother lode of local mineral lore. Pegmatite is the mother lode. Pegmatite is an igneous rock; in these mountains, the uplift of rock and eons of erosion put pegmatite close to the surface and make it easy to mine.

The QUARTZ Corp is a key supplier of the high purity Spruce Pine quartz sand for the solar, semiconductor, PVs, and fibre optic technology that go to the solar panels, lighting, computers, mobile phones, tabs and consoles all over the world. They have access to more than 10 million tonnes of high purity quartz resources in Spruce Pine, which is blasted out of the ground and take for initial processing at facility in Spruce Pine. Once this initial processing has been completed, the products are shipped to the plant in Drag, Norway.

The next step is sizing, where the raw material is crushed, ground to uniform sizes, and floated to start the purification.

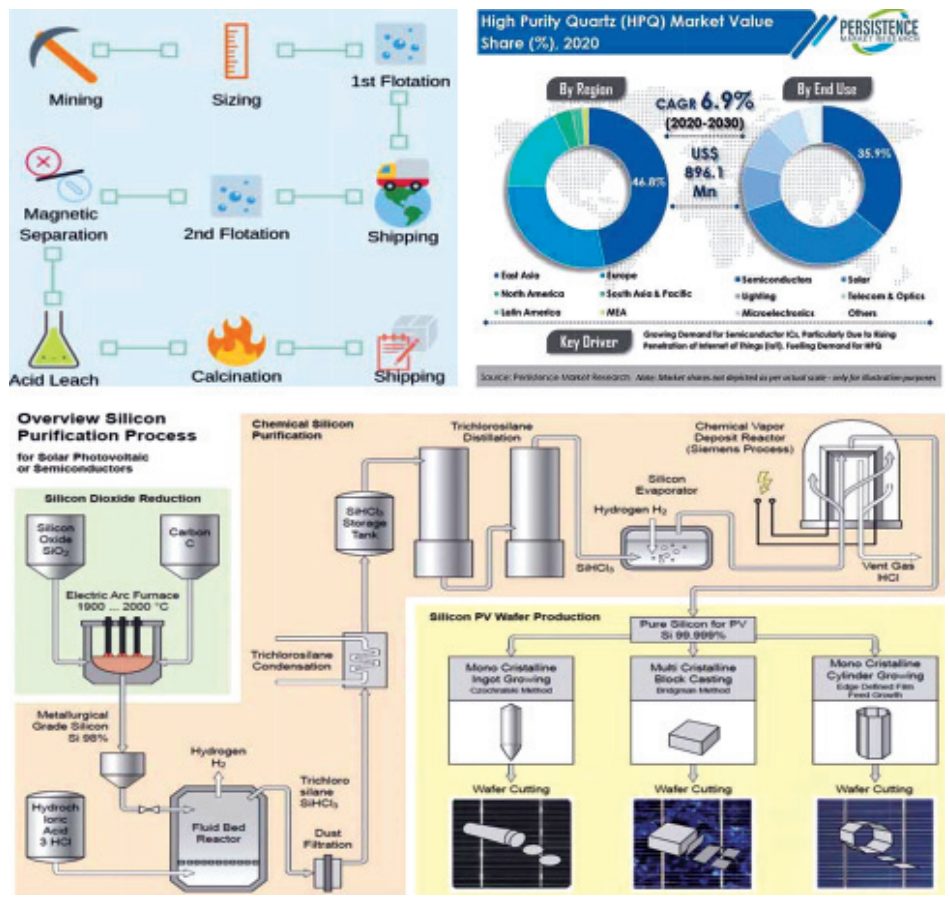

The Quartz's journey from the mines to becoming the wafers in PCB and industry growth projections

The advanced purification takes place, starting with flotation, where chemicals and air are used to remove traces of non-quartz impurities, such as feldspar and mica, from the product. After flotation, the product goes through magnet separation in order to remove ferrous contaminants. Leaching is another important processing step, which helps remove any remaining surface inclusions and impurities in the quartz grains using acid. To remove any residual organic contaminants, the quartz goes through thermal processing, known as calcination. Once these processing steps have been completed, the final product is ready! The Drag Norway facility's state-of-the-art production center enables it to produce quartz which is $99.998 \% \mathrm{SiO} 2$, valued currently at about $\$ 500$ - $\$ 1,000.00$ per tonne. 